\title{
EFFECT OF USING COPPER SLAG AS A BACKFILL IN RETAINING
} WALL

\author{
M.Sathya $^{1}$, B.Shanmugavalli ${ }^{2}$ \\ ${ }^{1}$ Assistant Professor, Department of Civil Engineering, Sethu Institute of Technology, Virudhunagar \\ ${ }^{2}$ Assistant Professor, Department of Civil Engineering, Sethu Institute of Technology, Virudhunagar
}

\begin{abstract}
Copper slag is obtained as a waste product after undergoing several industrial processes in Sterlite Industries. This slag is currently being used for many purposes like land filling, construction of abrasive tools, roofing granules, cutting tools and rail road ballast material etc. Since copper slag has higher shear strength and density, it can be used as backfill material in retaining walls. This study mainly aims to stabilize slope in retaining walls against seismic forces using copper slag as backfill material and also presents the results of shaking table tests on model rigid face reinforced soil retaining wall in the laboratory. The influence of copper slag backfill on the seismic response was studied through a series of laboratory model test on retaining wall and also compared with sand results. The wall constructed with copper slag backfill showed lesser faces deformations and lower at higher base excitation. Here the influence of copper slag on lateral earth pressure and displacement on retaining wall was studied for various proportions from $0 \%$ to $100 \%$. The results obtained from this study are helpful in understanding the dynamic performance of copper slag and sand backfill, when subjected seismic lateral earth pressure.
\end{abstract}

Keywords- Copper slag, backfill, earth pressure, shake table, seismic, retaining wall

\section{INTRODUCTION}

Environmental pollution is the major problem associated with rapid industrialization, urbanization and rise in living standards of people. Waste reduction and reuse have recently become the most preferable methods in solid waste management. Over recent decade's intensive research study have been carried out to explore all possible reuse methods of a wide range of waste materials. Copper slag is considered as one of the waste material generated during the production of copper which can have a promising future in construction industry. For every ton of copper produced about 2.2 ton of slag is generated. Nearly 24.5 million tons of copper slag is generated worldwide. In India, production is about 10 lakhs tones/annum. Copper slag is currently being used for many purposes like land filling, construction of abrasive tools, roofing granules, cutting tools and rail road ballast material, which are not very high value added application. These applications utilize only about $15 \%$ to $20 \%$ of copper slag generated and remaining material is dumped as a waste, which requires large areas of land. This paper deals with the feasibility of copper slag as a backfill material in retaining walls and the dynamic performance of copper slag due to lateral earth pressure.

Several studies have been reported experimentally about the response of retaining wall models with different backfilling materials. G. Madhavi Latha and A. Murali Krishna (2007), investigated that the influence of relative density of the backfill soil on the seismic response of reinforced soil wall models. The response of reinforced soil wall models subjected to face excitation is compared in terms of lateral displacement of the facing. The effects of facing rigidity were also evaluated to a limited extend. This observation clearly implies that the damage to retaining walls will be more in case of stronger seismic events, if the backfill is not properly compacted. Nova-Roesing and Sitar(2007), investigated the dynamic behavior of soil slopes reinforced with geo synthetics and metal grits using centrifuge test and observed that the magnitude of deformation is related to the backfill densities, reinforcement stiffness and spacing and slope inclination. El-Emam .M \& Bathrust. R. J (2004), experimentally investigated on the design and instrumentation of the series of physical experiments that has successfully used to investigate the response of reduced scale reinforced soil wall model to base excitation simulating earthquake.

\section{MATERIALS AND METHODS}

\subsection{Materials}

The Copper slag used as a backfill material in this study was obtained as a final waste product from Sterlite industries, Tuticorin, Tamilnadu. It was obtained as a result of manufacturing of copper electrodes in that industry. The copper slag appears like glassy granules having black colored texture. The following tables I and II shows chemical and physical properties of copper slag.

Table 1 Chemical properties of Copper Slag

\begin{tabular}{|l|l|}
\hline Chemical compounds & \% \\
\hline $\mathrm{SiO} 2$ & 25.84 \\
\hline $\mathrm{Fe} 2 \mathrm{O} 3$ & 68.29 \\
\hline $\mathrm{Al} 2 \mathrm{O} 3$ & 0.22 \\
\hline $\mathrm{CaO}$ & 0.15 \\
\hline $\mathrm{Na} 2 \mathrm{O}$ & 0.58 \\
\hline
\end{tabular}




\begin{tabular}{|l|l|}
\hline K2O & 0.23 \\
\hline $\mathrm{Mn} 2 \mathrm{O} 3$ & 0.22 \\
\hline $\mathrm{TiO} 2$ & 0.41 \\
\hline $\mathrm{SO} 3$ & 0.11 \\
\hline $\mathrm{CuO}$ & 1.2 \\
\hline Sulphide sulphur & 0.25 \\
\hline Insoluble residue & 14.88 \\
\hline Chloride & 0.018 \\
\hline
\end{tabular}

Table 2 Physical properties of Copper Slag

\begin{tabular}{|l|l|}
\hline Physical Properties & Copper slag \\
\hline Particle shape & Irregular \\
\hline Appearance & Black \& glassy \\
\hline Type & Air cooled \\
\hline Specific gravity & 3.91 \\
\hline Percentage of voids \% & 35 \\
\hline Bulk density g/cc & 2.08 \\
\hline Fineness modulus of copper slag & 3.47 \\
\hline Angle of internal friction & $51^{\circ} 20^{\circ}$ \\
\hline Ultimate shear stress $\mathrm{kg} / \mathrm{cm}^{2}$ & 0.4106 \\
\hline Water absorption \% & 0.15 to 0.20 \\
\hline Moisture content \% & 0.1 \\
\hline
\end{tabular}

\subsection{Mix Design}

The application of copper slag as a backfill material to reduce the seismic earth pressure was studied by conducting shake table test. For conducting shake table test, the backfill materials were prepared by varying the proportions of copper slag and sand. Copper slag proportion is varied from $0 \%$ to $100 \%$ for the replacement of sand named as $\mathrm{S100}$, CS10,CS20, CS30, CS40, CS50, CS60, CS70, CS80, CS90, CS100.

\subsection{Instrumentation}

The shake table consists of a flywheel, a camshaft, a vibration table and user designed cams. The maximum payload of the shake table is $30 \mathrm{~kg}$ and the table having dimension as $400 \mathrm{~mm} \times 300 \mathrm{~mm}$. The dimension of circular mounting plate is $390 \mathrm{~mm}$. The variable speed DC motor, having power of 1 H.P is used. The frequency range is controlled up to $3 \%$. The cam is connected to a variable speed DC motor with a help of a camshaft. The frequency range of the cam is $0-25 \mathrm{~Hz}$ and is having allowable frequency rang as $\pm 1.0 \mathrm{~mm}$. A data acquisition system accelerometer with digital vibration meter of size $15 \mathrm{~mm}$ is used. Velocity, Acceleration, RMS value, Peak value, Data hold, Maximum and Minimum value and other parameters can be measured using the data acquisition system. The velocity range is 20 and $200 \mathrm{~mm} / \mathrm{s}$, the acceleration range is 200 and $2000 \mathrm{~m} / \mathrm{s}$ and the frequency range is $40 \mathrm{~Hz}-1 \mathrm{KHz}$.

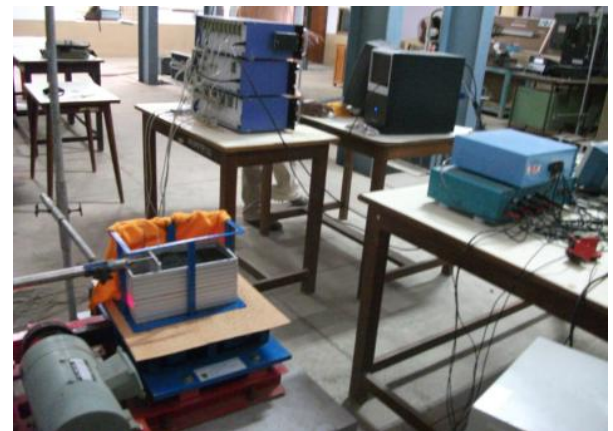

Fig. 1 Experimental Set-Up

\section{RESULTS AND DISCUSSION}

\subsection{Direct Shear Test}

Direct shear test was conducted to ascertain the shear resistance of copper slag. From cumulative graph Fig.2, it is inferred that the copper slag is having the highest angle of internal friction value $(\varphi)$ compare to sand. By increasing the copper slag proportion in the mix, the $\varphi$ value is also increasing. The angle of internal friction for $100 \%$ copper slag is 51 degrees whereas it is approximately 41 degrees for sand. Therefore it can be understood that the copper slag has higher shear strength than sand, which is the key parameter in resisting lateral seismic earth pressure. The increase of shear strength induced by the hardening is presumed to reduce the earth pressure. Since copper slag having greater shear strength it could be also used as a back fill material in retaining walls. Retaining walls are normally used to resist lateral earth pressures on bridges and embankments.

\subsection{Shake Table Test}

From shake table experiments the acceleration of sand, copper slag and various proportions of slag \& sand as a backfill material were measured using accelerometers. The graph showing the relation between frequency and displacement was drawn and is illustrated in Fig. 3.

The total earth pressure of the retaining wall model for various proportions was determined using Rankine's theory and those values are tabulated in Table. 4 and is illustrated in Fig. 4.

\section{CONCLUSIONS}

In this study, an attempt was made to utilize industrial waste products as a backfill material in Retaining wall. The percentage replacements varied from $0 \%$ to $100 \%$.Various tests were performed and results were obtained. Graphs were drawn for different proportions of copper slag and shear strengths obtained. The influence of copper slag on the seismic response of Retaining wall model was examined and the following conclusions were derived.

* Since copper slag contains higher $\mathrm{Fe}_{2} \mathrm{O}_{3}$ content, density of copper slag is $22 \%$ higher than sand.

* Unit weight of copper slag was obtained as 20.44 $\mathrm{kN} / \mathrm{m}^{3}$ whereas for sand it was $16.44 \mathrm{kN} / \mathrm{m}^{3}$. 
From Direct shear test and tri-axial shear test, the shear strength of CS100 was obtained $0.4106 \mathrm{~kg} / \mathrm{cm}^{2}$ whereas for sand (S100), it was only $0.299 \mathrm{~kg} / \mathrm{cm}^{2}$. Therefore this result shows that copper slag has higher shear resistance than that of sand.

Table 3 Direct Shear Test Readings

\begin{tabular}{|c|c|c|c|}
\hline $\begin{array}{l}\% \\
\text { Replacement } \\
\text { of copper slag }\end{array}$ & $\begin{array}{l}\text { Normal } \\
\text { stress } \\
\left(\mathrm{kg} / \mathrm{cm}^{2}\right)\end{array}$ & $\begin{array}{l}\text { Shear } \\
\text { strength } \\
\left(\mathrm{kg} / \mathrm{cm}^{2}\right)\end{array}$ & $\begin{array}{l}\text { Angle of } \\
\text { internal } \\
\text { friction }\end{array}$ \\
\hline \multirow{4}{*}{0} & 0.1 & 0.066 & \multirow{4}{*}{$40^{\circ} 36$} \\
\hline & 0.2 & 0.142 & \\
\hline & 0.3 & 0.23 & \\
\hline & 0.4 & 0.39 & \\
\hline \multirow{4}{*}{10} & 0.1 & 0.061 & \multirow{4}{*}{$41^{\circ} 59^{\prime} 13$} \\
\hline & 0.2 & 0.117 & \\
\hline & 0.3 & 0.201 & \\
\hline & 0.4 & 0.459 & \\
\hline \multirow{4}{*}{20} & 0.1 & 0.092 & \multirow{4}{*}{$42^{\circ} 36^{\prime} 50$} \\
\hline & 0.2 & 0.207 & \\
\hline & 0.3 & 0.357 & \\
\hline & 0.4 & 0.384 & \\
\hline \multirow{4}{*}{30} & 0.1 & 0.11 & \multirow{4}{*}{$43^{\circ} 3{ }^{\prime} 52^{\prime \prime}$} \\
\hline & 0.2 & 0.22 & \\
\hline & 0.3 & 0.357 & \\
\hline & 0.4 & 0.502 & \\
\hline \multirow{4}{*}{40} & 0.1 & 0.16 & \multirow{4}{*}{$44^{\circ} 42^{\prime} 44^{\prime \prime}$} \\
\hline & 0.2 & 0.23 & \\
\hline & 0.3 & 0.309 & \\
\hline & 0.4 & 0.435 & \\
\hline \multirow{4}{*}{50} & 0.1 & 0.107 & \multirow{4}{*}{$46^{\circ} 7^{\prime} 23^{\prime \prime}$} \\
\hline & 0.2 & 0.17 & \\
\hline & 0.3 & 0.26 & \\
\hline & 0.4 & 0.395 & \\
\hline \multirow{4}{*}{60} & 0.1 & 0.088 & \multirow{4}{*}{$47^{\circ} 27^{\prime} 50^{\prime \prime}$} \\
\hline & 0.2 & 0.17 & \\
\hline & 0.3 & 0.277 & \\
\hline & 0.4 & 0.41 & \\
\hline \multirow{4}{*}{70} & 0.1 & 0.087 & \multirow{4}{*}{$47^{\circ} 27^{\prime} 56^{\prime \prime}$} \\
\hline & 0.2 & 0.206 & \\
\hline & 0.3 & 0.302 & \\
\hline & 0.4 & 0.41 & \\
\hline \multirow{4}{*}{80} & 0.1 & 0.11 & \multirow{4}{*}{$47^{\circ} 43^{\prime} 34^{\prime \prime}$} \\
\hline & 0.2 & 0.213 & \\
\hline & 0.3 & 0.32 & \\
\hline & 0.4 & 0.406 & \\
\hline \multirow{4}{*}{90} & 0.1 & 0.12 & \multirow{4}{*}{$49^{\circ} 23^{\prime} 55^{\prime \prime}$} \\
\hline & 0.2 & 0.206 & \\
\hline & 0.3 & 0.324 & \\
\hline & 0.4 & 0.396 & \\
\hline \multirow{4}{*}{100} & 0.1 & 0.116 & \multirow{4}{*}{$51^{\circ} 25^{\prime}$} \\
\hline & 0.2 & 0.266 & \\
\hline & 0.3 & 0.377 & \\
\hline & 0.4 & 0.44 & \\
\hline
\end{tabular}




\section{Normal stress Vs Ultimate shear strength}

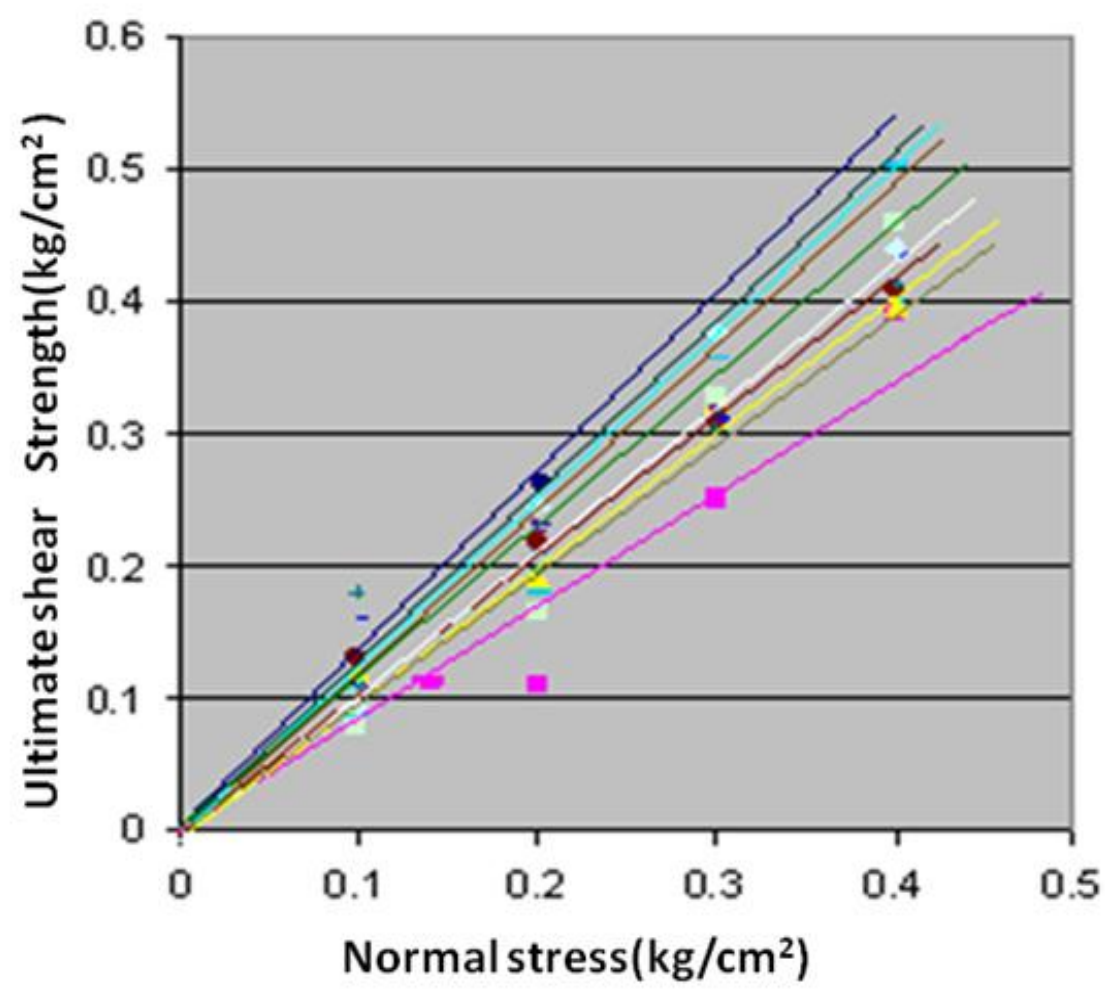

4 slag100\%

= sand $100 \%$

slag $90 \%$ send $10 \%$

slag $80 \%$ sand $20 \%$

$x$ slag $70 \%$ send $30 \%$

- slag60\% sand $40 \%$

+ slag $50 \%$ send $50 \%$

-slag $40 \%$ send $60 \%$

- slag $30 \%$ send $70 \%$ slag $20 \%$ sand $80 \%$ slag10\%sand $90 \%$

Fig 2 Direct shear test graph for various proportions of slag \&sand

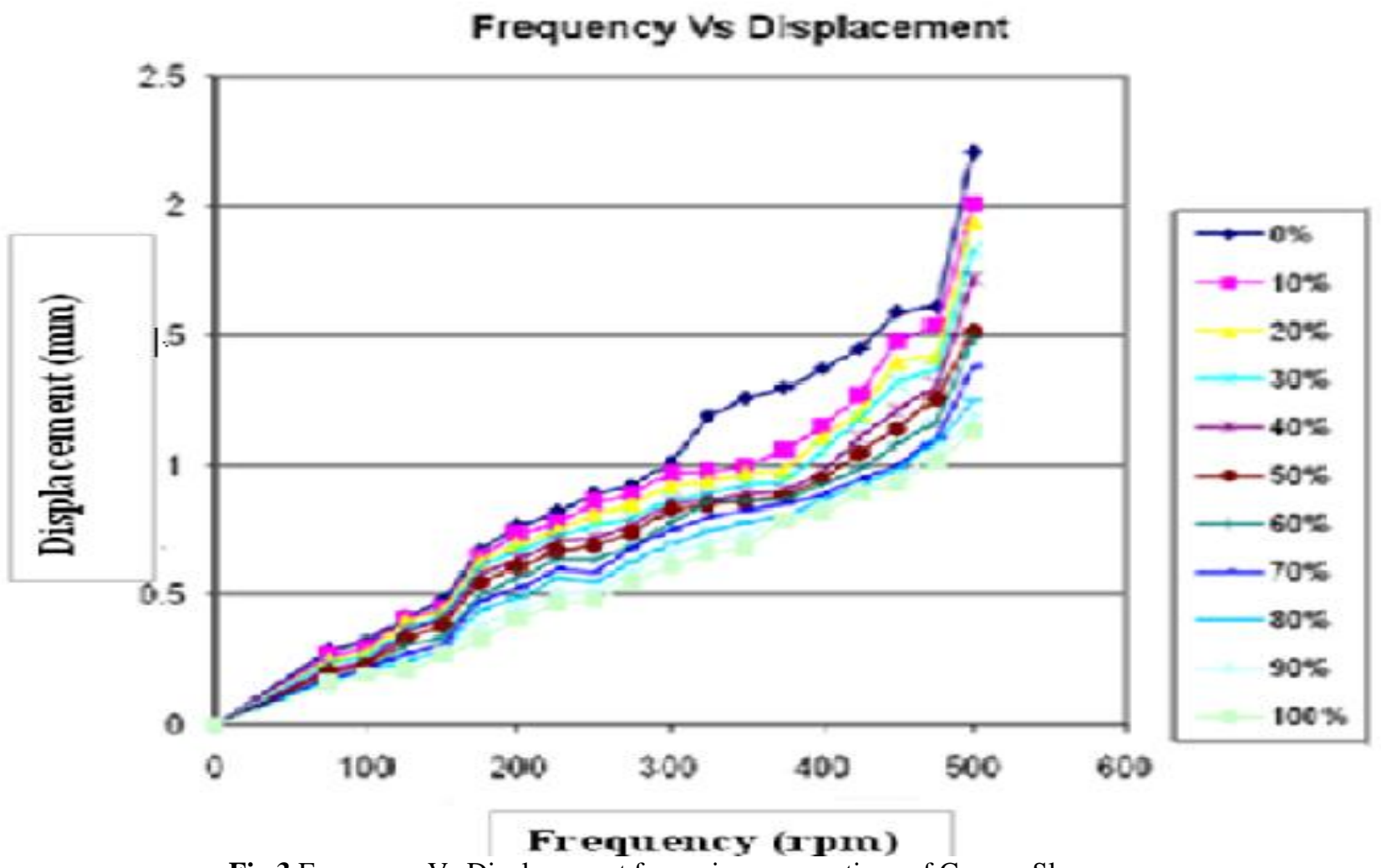

Fig 3 Frequency Vs Displacement for various proportions of Copper Slag 
Table 4 Earth Pressure Calculations using Rankine's Theory

\begin{tabular}{|l|l|l|l|l|l|}
\hline $\begin{array}{c}\text { Mixing } \\
\text { identity }\end{array}$ & $\begin{array}{c}\text { Unit weight } \\
(\gamma) \mathbf{k N} / \mathbf{m}^{\mathbf{3}}\end{array}$ & $\begin{array}{c}\text { Effective vertical } \\
\mathbf{s t r e s s}\left(\mathbf{\sigma}_{\mathbf{v}}\right) \mathbf{k N} / \mathbf{m}^{2}\end{array}$ & $\begin{array}{c}\text { Co-efficient of } \\
\text { Active earth } \\
\mathbf{p r e s s u r e} \\
\left(\mathbf{K}_{\mathbf{a}}=(\mathbf{1}-\mathbf{s i n} \phi) /(\mathbf{1}\right. \\
+\mathbf{s i n} \phi))\end{array}$ & $\begin{array}{c}\text { Total horizontal stress } \\
\left(\mathbf{\sigma}_{\mathbf{h}}=\mathbf{K}_{\mathbf{a}} \mathbf{X} \mathbf{\sigma}_{\mathbf{v}}\right) \mathbf{k N} / \mathbf{m}^{2}\end{array}$ & $\begin{array}{c}\text { Total Active earth } \\
\text { pressure of the wall } \\
\left(\mathbf{P}_{\mathbf{a}}=\mathbf{1} / \mathbf{2}^{*} \mathbf{\sigma}_{\mathbf{h}} * \mathbf{H}\right) \\
\mathbf{k N} / \mathbf{m}\end{array}$ \\
\hline S100 & 16.44 & 2.51 & 0.212 & 0.533 & 0.041 \\
\hline CS10 & 16.84 & 2.57 & 0.198 & 0.509 & 0.038 \\
\hline CS20 & 17.24 & 2.62 & 0.192 & 0.504 & 0.037 \\
\hline CS30 & 17.64 & 2.64 & 0.188 & 0.497 & 0.036 \\
\hline CS40 & 18.04 & 2.73 & 0.174 & 0.475 & 0.035 \\
\hline CS50 & 18.44 & 2.79 & 0.162 & 0.452 & 0.033 \\
\hline CS60 & 18.84 & 2.84 & 0.152 & 0.433 & 0.032 \\
\hline CS70 & 19.24 & 2.89 & 0.151 & 0.430 & 0.032 \\
\hline CS80 & 19.64 & 2.95 & 0.146 & 0.429 & 0.031 \\
\hline CS90 & 20.04 & 3.01 & 0.136 & 0.412 & 0.0309 \\
\hline CS100 & 20.44 & 3.06 & 0.122 & 0.373 & 0.027 \\
\hline
\end{tabular}

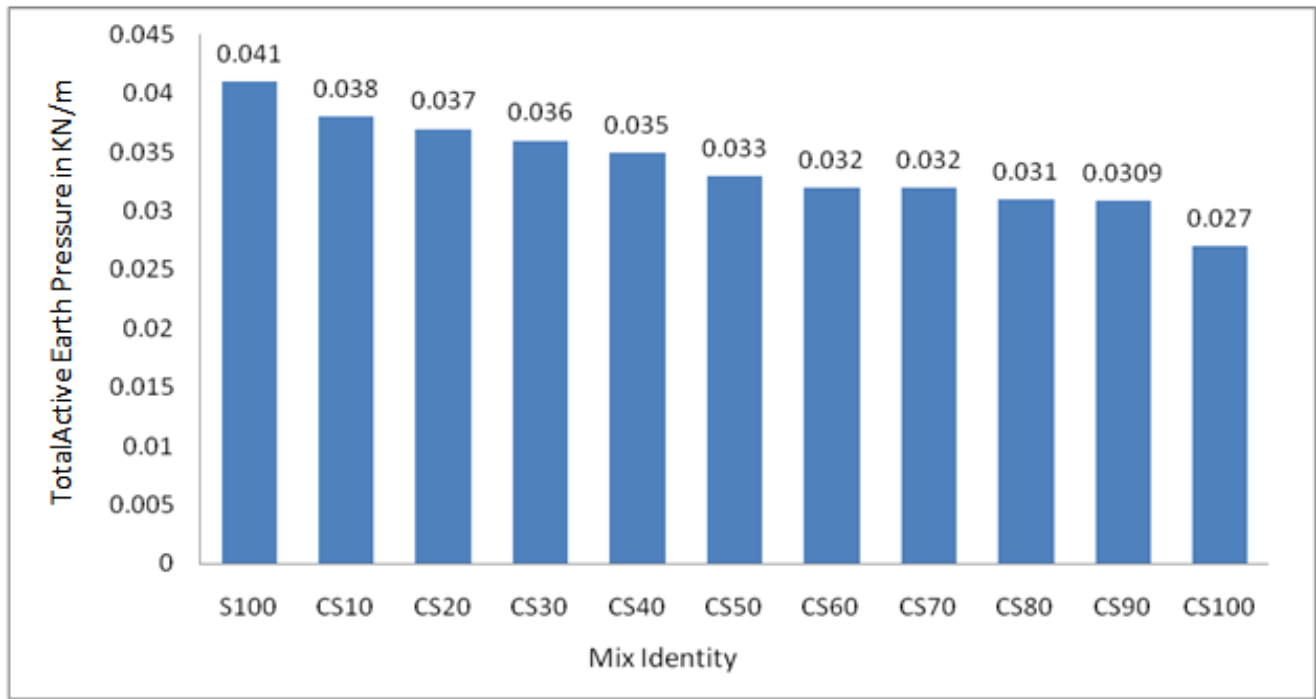

Fig. 4 Earth Pressure Comparison For Various Proportions of Copper Slag

* Angle of internal friction of backfill material is increased when copper slag has been used as backfill material. $\Phi$ value obtained for copper slag is $51^{\circ}$ $20^{\prime}$ and for sand $40^{\circ} 36^{\prime}$. This parameter is the main factor in reducing seismic earth pressure in retaining walls.

* From shake table test, it is observed that the acceleration of copper slag backfill is very small compared with sand backfill, even at higher base excitation.

* Displacement test results represents that there is a significant decrease in displacement of retaining wall model, while using copper slag used as a backfill material.

* The maximum displacement of CS100 was obtained as $1.13 \mathrm{~mm}$ whereas for $\mathrm{S} 100$, the maximum displacement was $2.21 \mathrm{~mm}$. Therefore from this result it can be concluded that copper slag is reduced the displacement of retaining wall when used as backfill material.

* Seismic shake table test results shows that the lateral earth pressure acting on retaining wall is reduced when copper slag used as backfill material. Even though copper slag has higher density than sand , because of its higher shear strength and angle of internal friction, the seismic lateral earth pressure is greatly reduced.

* From these results, it can be concluded that copper slag is a good backfill material than sand and it can be used as backfill in retaining walls. 


\section{REFERENCES}

[1] Awad Al-Karni and Abdulhafiz Alshenawy,"Modeling of Stress- Strain Curves of Drained Triaxial Test on Sand".

[2] El-emam.m.\&bathrust.r.j," Experimental design, instrumentation \& interpretation Of Reinforced soil wall response using a shaking table. International Journal of Physical Modelling in Geotechnics.(2004)

[3] C.C. Huang; S.-H. Wu; and H.-J. Wu ,"Seismic Displacement Criterion for Soil Retaining WallsBased on Soil Strength Mobilization".

[4] Hatami, K., Bathurst, R.J., "Effect of structural design on fundamental frequency of reinforced-soil retaining walls". Soil Dynamics and Earthquake Engineering (2000)

[5] Huang, C. C., Tateyama, M., Kato, N., and Tatsuoka, F. "Model shaking tests of soil retaining walls situated on sand slope." Geosynth.Eng(2000)

[6] Karpurapu, R., Bathurst, R.J.,"Numerical investigation of controlled yielding of soil-retaining wall structures", Geotextiles and Geomembranes (1992)

[7] Lee,K.Z.Z.,Wu,J.T.H.,"Synthesis of case histories on GRS bridge supporting structures with flexible facing". Geotextiles and Geomembranes,(2004)

[8] G.Madhavi Latha, A.Murali Krishna, "Seismic response of reinforced soil retaining wall models:Influence of backfill relative density", 'Geotextiles and Geomembranes'.(2007).

[9] Matsuo, O., Tsutsumi, T., Yokoyama, K., Saito, Y.," Shaking table tests and analysis of geosynthetic-reinforced soil retaining walls".(1998).

[10] Nova - Roesing and sitar," Centrifuge model studies of the seismic response of reinforced soil slopes", Journal of Geotechnical and Geoenvironmental Engineering.(2007)

[11] Orense, R. P., Morimoto, I., Y., Yumiyama, T. Yamamoto, H. and Sugawara, K., "Study on walltype gravel drains as liquefaction countermeasure for underground structures", Soil Dyn.Earthquake Eng., (2003)

[12] S. K. Prasad,, I. Towhata, G. P. Chandradhara and P. Nanjundaswamy," Shaking table tests in earthquake geotechnical Engineering".

[13] Sukeo-O-Hra \& Hiroshi Matsuda, "Studies on earth pressure of cohesive backfill".

[14] Wartman, J., Seed, R. B., and Bray, J. D. _2005_. "Shaking table modeling of seismically induced deformations in slopes." J. Geotech \&Geoenviron. Eng., (2005).

[15] Yogendrakumar, M., Bathurst, R. J., and Finn, W. D. L. "Dynamic response analysis of reinforced soil retaining wall." (1992) 